\title{
The World Journal of Surgery Welcomes Dr. Michaela A. West to the Editorial Board
}

\author{
Julie Ann Sosa ${ }^{1}$
}

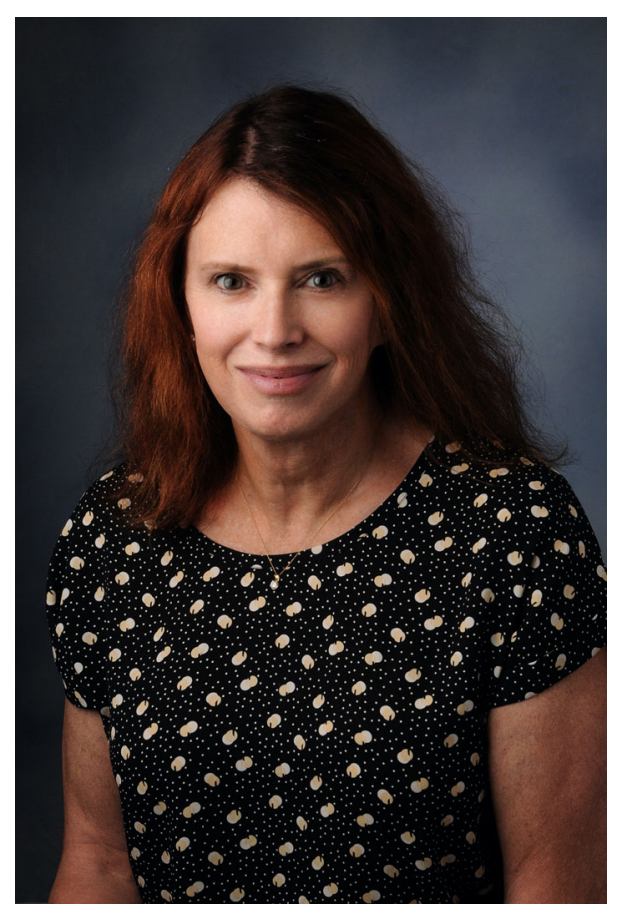

Dr. Michaela A. West, MD, PhD, grew up in eastern Wisconsin in the USA. She received her undergraduate education at the University of Wisconsin-Madison, is a graduate of Loyola-Stritch School of Medicine in Chicago, and she obtained her surgical/critical care training and $\mathrm{PhD}$ at the University of Minnesota in Minneapolis. She is a Board-Certified general surgeon and surgical intensivist with extensive experience in general, emergency, and trauma surgery, and she has been a member of the academic surgical faculty at Washington University, University of Minnesota, Northwestern University, and the University of California San Francisco. Dr. West currently serves as the Trauma Research Chair at North Memorial Health Care, a Level 1 Trauma Center in Minneapolis, MN. Dr. West is an Emeritus Professor University of California San Francisco and currently an Adjunct Professor of Surgery at the University of Minnesota. During her career, she has authored or coauthored more than 250 peer-reviewed papers and other publications concerning sepsis, surgical infections, and a variety of other topics. More recently, she has also focused on diversity issues in surgery and medicine. Dr. West has had a lifelong passion for skiing and travel. She is a certified ski instructor and a proud grandparent of 7 grandchildren.

Twitter handle is@MichaelaWst

Publisher's Note Springer Nature remains neutral with regard to jurisdictional claims in published maps and institutional affiliations.
Julie Ann Sosa, MD, MA, FACS—Editor in Chief, World Journal of Surgery.

Julie Ann Sosa

julie.sosa@ucsf.edu

1 University of California at San Francisco-UCSF, San Francisco, USA 